\title{
Resistance to extended-spectrum cephalosporins, caused by PER-1 $\beta$-lactamase, in Salmonella typhimurium from Istanbul, Turkey
}

\author{
H. VAHABOGLU, L. M. C. HALL*, L. MULAZIMOGLU, S. DODANLI, I. YILDIRIM and \\ D. M. LIVERMORE*
}

Infectious Diseases Service, Taksim Hastanesi, Sirase/viler cadd., Cihangir, Istanbul, 80060 Turkey and * Department of Medical Microbiology, The London Hospital Medical College, Turner Street, London E1 2AD

\begin{abstract}
Summary. Two Salmonella typhimurium isolates were studied, one as a representative from a series of neonatal meningitis cases treated at an Istanbul teaching hospital, the other from a gastro-enteritis case seen at a different Istanbul hospital. Both isolates were resistant to extended-spectrum cephalosporins, as well as penicillins, aminoglycosides and chloramphenicol. Cephalosporin resistance depended on production of PER-1 $\beta$-lactamase, which is an extended-spectrum class A enzyme that is only distantly related to TEM and SHV enzymes, and which was previously known only from Pseudomonas aeruginosa isolates. The PER-1 gene was carried by an 81-MDa plasmid, which also determined resistance to aminoglycosides and chloramphenicol. Although it was not self-transmissible to Escherichia coli, this element did transfer if mobilised with plasmid pUZ8. The two $S$. typhimurium isolates gave indistinguishable DNA restriction patterns and, in addition to their $81-\mathrm{MDa}$ plasmid, also contained 52- and 2-8-MDa plasmids, the last of these encoded TEM-1 enzyme. The two isolates were identical in serotype, antibiogram and plasmid-profile but nevertheless differed in phage type, and, therefore, represented distinct strains. The emergence of cefotaxime and ceftriaxone resistance in salmonellae is disturbing, since these agents are preferred therapy for neonatal meningitis caused by members of the genus.
\end{abstract}

\section{Introduction}

Salmonella infections are frequent throughout the developing world and are a major health concern in Istanbul, Turkey. ${ }^{1}$ Besides causing self-limiting gastroenteritis, salmonellae are also responsible for invasive diseases, including bacteraemia and neonatal meningitis. Ampicillin and chloramphenicol have long been the first-line treatments for invasive salmonella infections, but increasing resistance means these drugs can no longer be recommended in many developing countries, including Turkey. Alternative therapies include quinolones and two cephalosporins, cefotaxime and ceftriaxone. Quinolones are preferred for most salmonella infections, but the cephalosporins may be better in neonatal meningitis, because quinolones penetrate the CSF poorly and can adversely affect cartilage development. ${ }^{2}$ Unfortunately, however, cephalosporin-resistant salmonellae have been reported from North Africa and Malaysia. ${ }^{3-5}$
These isolates owed their resistance to extendedspectrum mutants of TEM or SHV $\beta$-lactamases. We now describe cephalosporin-resistant $S$. typhimurium isolates from Istanbul. These produced PER-1 $\beta$ lactamase, an extended-spectrum type that is only distantly related to the TEM and SHV enzymes, and which previously was known only from Pseudomonas aeruginosa isolates. ${ }^{6}$

\section{Materials and methods}

\section{Patients and isolates}

Four neonates, who were born over a 4-month period in the same delivery room of an Istanbul teaching hospital, each developed S. typhimurium meningitis 1-17 days after birth, and were admitted to the neonatal intensive care unit of the hospital (table I).

No source of the infections was identified, although carriage by staff was suspected. The isolates were 
Table I. Characteristics of the neonates with salmonella meningitis

\begin{tabular}{|c|c|c|c|c|c|}
\hline \multirow{2}{*}{ Patient no. } & \multicolumn{3}{|c|}{ Admission } & \multirow{2}{*}{$\begin{array}{l}\text { Day* ciprofloxacin } \\
\text { started }\end{array}$} & \multirow{2}{*}{ Outcome } \\
\hline & Date & Weight $(\mathrm{kg})$ & Age (days) & & \\
\hline 1 & $18 / 11 / 92$ & $2 \cdot 55$ & 4 & 8 & Died \\
\hline 2 & $23 / 01 / 93$ & $2 \cdot 70$ & 17 & 2 & Survived \\
\hline 3 & $16 / 03 / 93$ & $3 \cdot 10$ & 1 & Not used & Died \\
\hline $4 \dagger$ & $16 / 03 / 93$ & 1.95 & 6 & 4 & Died \\
\hline
\end{tabular}

*Day post-diagnosis of meningitis.

$\dagger$ Patient from whom isolate D was obtained.

resistant to chloramphenicol, ampicillin, cefotaxime and ceftriaxone, but were susceptible to ciprofloxacin (see Results). Three of the neonates were treated with ciprofloxacin $(10 \mathrm{mg} / \mathrm{kg}$ 12-hourly), but only one survived. The serotypes, biotypes, antibiotic resistance patterns and plasmid profiles of the isolates from the four patients were identical and one, designated " $D$ ", was chosen for study. The other cephalosporinresistant $S$. typhimurium isolate studied here, designated "B", was from a patient who presented with gastro-enteritis at a hospital on the other side of the Bosphorus to the neonatal unit. (The Bosphorus is a sea channel that connects the Sea of Marmara to the Black Sea, thereby separating Europe and Asia and dividing Istanbul into two halves). No epidemiological link was identified between this patient and those seen in the neonatal unit.

Isolates B and D were identified with API 20E strips (bioMérieux, La Balme les Grottes, France) and were serotyped by slide agglutination tests with $\mathrm{O}-, \mathrm{H}_{1}$ - and $\mathrm{H}_{2}$-specific antisera. Serotyping results were reconfirmed by the Salmonella Section of the National Microbiology Institute of Turkey, and by the Laboratory of Enteric Pathogens, Central Public Health Laboratory, Colindale, London. The latter establishment also undertook phage typing.

Escherichia coli $\mathrm{K}-12$ J53-1 pro, $\mathrm{Nal}^{\mathrm{r}^{7}}$ was used as a recipient in transfer experiments. Plasmid pUZ8 ${ }^{8}$ encoding resistance to kanamycin, tetracycline and mercurials, was used as mobilising plasmid. E. coli NCTC $50192,{ }^{9}$ that contains plasmids of $98,42,23.9$ and $4.6 \mathrm{MDa}$, was used as a source of markers for plasmid electrophoresis. Reference producers of TEM-1, TEM-2 and SHV-1 $\beta$-lactamases were from our strain collection, and E. coli JM109 with plasmid pPZ1 ${ }^{6}$ encoding PER-1 enzyme, was generously provided by $P$. Nordmann, Paris.

\section{Antibiotics and susceptibility tests}

Antibiotics were from suppliers as follows: chloramphenicol, ciprofloxacin and sulphamethoxazole from Sigma; ampicillin sodium and clavulanate lithium from SmithKline Beecham, Brentford, Middlesex; ceftriaxone from Roche, Welwyn Garden City, Hertfordshire; piperacillin sodium and tazobactam from Lederle, Gosport, Hampshire; ceftazidime from Glaxo, Greenford, Middlesex; amikacin and aztreonam from Bristol-Myers Squibb, Syracuse, NY, USA; cefotaxime from Roussel, Uxbridge, Middlesex; cefoxitin and imipenem from Merck Sharp and Dohme, Hoddesdon, Hertfordshire; and meropenem from Zeneca, Macclesfield, Cheshire.

MICs were determined on IsoSensitest agar (Unipath) with inocula of $10^{4}-10^{5} \mathrm{cfu} / \mathrm{spot}$, delivered by a semi-automated multipoint inoculator (Mast, Merseyside). Results were evaluated after incubation for $18 \mathrm{~h}$ at $37^{\circ} \mathrm{C}$, and the MICs were read as the lowest concentrations to prevent growth completely.

\section{Plasmid analysis and detection of $\beta$-lactamase genes}

The rapid procedure of Kado and $\mathrm{Liu}^{10}$ was used to detect plasmids and to estimate their sizes. Briefly, plasmids were extracted from overnight cultures grown in nutrient broth and were electrophoresed at $12 \mathrm{~V} / \mathrm{cm}$ for $1-2 \mathrm{~h}$ in agarose $0.9 \%$ in TBE buffer, then stained with ethidium bromide. Size estimation was by comparison to the migration of the plasmids of strain NCTC 50192 . To detect the $\beta$-lactamase genes, the plasmid DNA was transferred to Hybond-N nylon membranes (Amersham International, Amersham, Buckinghamshire), by a positive-pressure blotter (Posiblot, Stratagene, Cambridge), and then hybridised with appropriate probes. The PER-1 gene probe was the PCR product of $b l a_{\mathrm{PER}-1}$ amplified, as described below, from a $P$. aeruginosa producer and labelled with digoxigenin by means of a random labelling kit (Dig DNA Labeling and Detection Kit, Boehringer, Lewes, E. Sussex). The bla $a_{\text {тем.1 }}$ probe was as described previously. ${ }^{11}$ Hybridisations were performed at $68^{\circ} \mathrm{C}$ under high-stringency conditions. ${ }^{12}$ Plasmids were isolated for transformation experiments by a mini-prep method. ${ }^{13}$

\section{Transconjugation and transformation}

For conjugation experiments, equal volumes of exponentially-growing nutrient-broth cultures of the $S$. typhimurium donors and the E. coli K-12 J53-1 recipient were mixed and spread on nutrient-agar plates. After overnight incubation at $37^{\circ} \mathrm{C}$, the growth was harvested into saline $0.9 \%$ and spread on nutrient agar containing nalidixic acid $100 \mathrm{mg} / \mathrm{L}$ plus either ceftazidime $32 \mathrm{mg} / \mathrm{L}$ or ampicillin $64 \mathrm{mg} / \mathrm{L}$, to select transconjugants. 
In some experiments, plasmid pUZ8 was first introduced into the salmonellae. This was achieved by plate-mating as above, but with $E$. coli J53-1 (pUZ8) as the donor and $S$. typhimurium strains B and D as recipients. Transconjugant selection was on nutrient agar containing tetracycline $64 \mathrm{mg} / \mathrm{L}$ plus ceftazidime $32 \mathrm{mg} / \mathrm{L}$. The pUZ8-containing salmonellae thereby obtained were then mated with $E$. coli K-12 J53-1, and transconjugants were selected, as above, on agar containing ceftazidime plus nalidixic acid.

$E$. coli $\mathrm{K}-12$ J53-1 cells were prepared as competent recipients for transformation by a standard method. ${ }^{12}$ Briefly, the bacteria from an exponentially growing broth culture were washed and resuspended in ice-cold $50 \mathrm{mM} \mathrm{CaCl}{ }_{2}$, then held at $0^{\circ} \mathrm{C}$ for $2 \mathrm{~h}$. Plasmids, prepared as above from the salmonellae, were then added and the cells were heat-shocked at $42^{\circ} \mathrm{C}$ for $2 \mathrm{~min}$. Transformants were selected on nutrient agar containing ceftazidime, $32 \mathrm{mg} / \mathrm{L}$.

\section{Extraction and iso-electric focusing of $\beta$-lactamases}

Overnight cultures from nutrient-agar plates or slopes were harvested into $0.01 \mathrm{M}$ phosphate buffer, $\mathrm{pH} 7 \cdot 0$, and $\beta$-lactamases were released by sonication. Debris was removed by centrifugation at $12000 \mathrm{~g}$ for $15 \mathrm{~min}$. The supernates were retained and subjected to iso-electric focusing at $15 \mathrm{~W}$ for $75-90 \mathrm{~min}$ on gels $(230 \mathrm{~mm} \times 100 \mathrm{~mm} \times 1 \mathrm{~mm})$ prepared essentially according to the formulation of Matthew et al., ${ }^{14}$ but supplemented with sucrose $10 \%$ as an osmotic buffer. After focusing, the $\beta$-lactamases were located by overlaying the gels with $1 \mathrm{mM}$ nitrocefin in $0.1 \mathrm{M}$

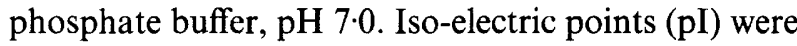
estimated by comparison to reference standards (PER1, SHV-1, TEM-1 and TEM-2 enzymes).

\section{$P C R$ and sequence analysis}

The primers for polymerase chain reaction (PCR) and sequence analysis of $b l a_{\mathrm{PER}-1}$ have been described elsewhere $^{15}$ and comprised: PER A : 5'-ATGAATGTCATTATAAAAGC; PER B: 5'-AGGTTTTAGAGAATACCTGG; PER C: 5'-ACACAGCTGTCTGAAACCTC; and PER D: (5' biotin)-AATTTGGGCTTAGGGCAAGAAA. PER A and PER D were used for amplification; PER A, PER B and PER C were used as sequencing primers. PCR was performed in $100-\mu 1$ reaction mixtures containing $2.5 \mathrm{U}$ of Taq polymerase (Perkin Elmer Cetus, Warrington, Lancashire), $2.5 \mathrm{mM} \mathrm{MgCl}_{2}, 0.2 \mathrm{mM}$ dNTPs and 20 pmol of each primer. Cycling, repeated 20 times, was at $94^{\circ} \mathrm{C}$ for $2 \mathrm{~min}, 50^{\circ} \mathrm{C}$ for $1 \mathrm{~min}$ and $72^{\circ} \mathrm{C}$ for $2 \mathrm{~min}$. A 926-bp PCR product was visualised on the ethidium bromidestained gels.

The nucleotide sequences of the PCR products from both $S$. typhimurium isolates were determined. The biotinylated strand was purified with paramagnetic beads, as described by the manufacturer (Dynabeads, Dynal, New Ferry, Wirral). Sequencing was achieved with a Sequenase Version $2.0 \mathrm{Kit}$, used according to the manufacturers' protocol (United States Biochemical Corp., Cleveland, OH, USA). Sequences were read on a sonic digitiser and processed with $\mathrm{PC} / \mathrm{Gene}$ software (Intelligenetics, Mountain View, CA, USA).

\section{Results}

\section{Characterisation of bacteria}

Isolates B and D gave identical API profiles (no. 6704752 ) and gave agglutination reactions with the following salmonella-specific antisera: $\mathrm{O}_{4,5,12}, \mathrm{H}_{\mathrm{i}}$, and $\mathrm{H}_{1,2}$. These are typical profiles for $S$. typhimurium. Despite their differing origins, isolates $B$ and $D$ had identical antibiograms, being resistant to penicillins, cephalosporins, aztreonam, aminoglycosides, chloramphenicol and sulphamethoxazole, although susceptible to imipenem, meropenem and tetracycline (table II). Ceftazidime resistance was reversed by clavulanate $4 \mathrm{mg} / \mathrm{L}$, but not by tazobactam $4 \mathrm{mg} / \mathrm{L}$. Iso-electric focusing revealed that both isolates produced $\beta$-lactamases that focused at $\mathrm{pI}$ values of 5.3 and $5 \cdot 4$ (fig. 1), although it was not immediately apparent whether these enzymes were distinct, or were satellites of a single type. Both isolates had plasmids of $c .81,52$ and 2.8 MDa (fig. 2). The 81-MDa plasmid hybridised with the PER-1 gene probe and the 2-8-MDa plasmid hybridised with the TEM gene probe.

Despite all their similarities the two isolates gave distinct phage reactions: isolate B was of phage type 29 and isolate D was of type 193 .

\section{Resistance transfer and characterisation of the transconjugants and transformants}

Strains $B$ and $D$ readily transferred ampicillin resistance to $E$. coli $\mathrm{K}-12 \mathrm{~J} 53-1$ in plate-mating experiments, and representative ampicillin-selected transconjugants were designated $E$. coli $\mathrm{K}-12$ J53-1 (B amp) and J53-1 (D amp), respectively. These transconjugants did not acquire resistance to extendedspectrum cephalosporins, chloramphenicol or aminoglycosides (table II). Iso-electric focusing revealed them to have acquired the pI $5.4 \beta$-lactamase, but not the pI 5.3 type. Plasmid electrophoresis detected the 52- and 2.8-MDa plasmids, but not the 81-MDa plasmid.

Cephalosporin resistance was conjugatively transferred from the salmonellae only if plasmid pUZ8 was first introduced into them. The transconjugants thereby obtained, designated E. coli K-12 J53-1 (B trcj) and J53-1 (D trcj), had qualitatively similar antibiograms to the donor salmonellae, except that they were less resistant to cefotaxime, ceftazidime and ceftazidime/tazobactam and remained fully susceptible to sulphamethoxazole. These transconjugants expressed both the pI 5.3 and $5.4 \beta$-lactamases and acquired three plasmids, with the same estimated mol. wts as those present in the donors. Tetracycline resistance, coded by $\mathrm{pUZ} 8$, was not retained in the 
Table II. Susceptibility of isolates, transconjugants and transformants

\begin{tabular}{|c|c|c|c|c|c|c|c|c|c|c|c|c|c|c|c|c|}
\hline \multirow{2}{*}{$\begin{array}{l}\text { Isolates, } \\
\text { trans- } \\
\text { conjugants } \\
\text { and } \\
\text { transformants }\end{array}$} & \multicolumn{16}{|c|}{$\mathrm{MIC}(\mathrm{mg} / \mathrm{L})$} \\
\hline & Amp & Pip & $\mathrm{Ctx}$ & $\mathrm{Ctr}$ & $\mathrm{Ctz}$ & $\begin{array}{l}\text { Ctz/ } \\
\text { Clav }\end{array}$ & $\mathrm{Ctz} / \mathrm{Taz}$ & Azt & $\operatorname{Imp}$ & Mem & Ak & $\mathrm{Gm}$ & Ch 1 & $\mathrm{Tc}$ & $\operatorname{Smx}$ & Cip \\
\hline J53-1 & 2 & $0 \cdot 25$ & 0.01 & $0 \cdot 01$ & 0.03 & 0.03 & 0.02 & 0.02 & 0.06 & $<0.02$ & 2 & $<0.125$ & 4 & 1 & 4 & 0.02 \\
\hline JM109(pPZ1)* & 64 & 2 & 1 & ND & 32 & 0.02 & 0.03 & 16 & 0.12 & $<0.02$ & 2 & $<0.125$ & 512 & 1 & ND & $0 \cdot 02$ \\
\hline Isolate B & $>1024$ & $>512$ & 128 & 128 & $>1024$ & 0.5 & $>256$ & 1024 & $0 \cdot 12$ & $<0.02$ & 32 & 16 & 512 & 2 & 64 & $0 \cdot 01$ \\
\hline J53-1(B amp) & $>1024$ & $>512$ & 0.01 & $0 \cdot 01$ & 0.06 & 0.02 & 0.03 & 0.03 & $0 \cdot 12$ & $<0.02$ & 2 & $<0.125$ & 2 & 1 & 4 & 0.01 \\
\hline $\mathrm{J} 53-1$ (B trcj) & $>1024$ & $>512$ & 8 & 32 & 256 & $0 \cdot 03$ & 16 & 256 & $0 \cdot 12$ & $<0.02$ & 16 & 8 & 512 & 1 & 8 & 0.01 \\
\hline J53-1(B trfm) & 512 & 16 & 8 & 64 & 256 & 0.03 & 1 & 128 & $0 \cdot 12$ & $<0.02$ & 32 & 8 & 512 & $<0.5$ & 64 & 0.01 \\
\hline Isolate D & $>1024$ & $>512$ & 128 & 128 & $>1024$ & 0.5 & $>256$ & 1024 & $0 \cdot 12$ & $<0.02$ & 32 & 16 & 512 & 2 & 32 & 0.01 \\
\hline J53-1(D amp) & $>1024$ & $>512$ & 0.01 & 0.01 & 0.06 & 0.03 & 0.03 & 0.06 & $0 \cdot 12$ & $<0.02$ & 2 & $0 \cdot 25$ & 2 & 1 & 4 & 0.01 \\
\hline J53-1(D trcj) & $>1024$ & $>512$ & 8 & 32 & 256 & 0.02 & 16 & 256 & $0 \cdot 12$ & $<0.02$ & 8 & 8 & 512 & 1 & 8 & 0.01 \\
\hline $\mathrm{J} 53-\mathrm{I}(\mathrm{D} \operatorname{trfm})$ & 512 & 16 & 8 & 32 & 128 & 0.02 & I & 256 & 0.06 & $<0.02$ & 8 & 8 & 512 & 1 & 64 & 0.01 \\
\hline
\end{tabular}

Amp, ampicillin; Pip, piperacillin; Ctx, cefotaxime; Ctr, ceftriaxone; Ctz, ceftazidime; Clav, clavulanate at $4 \mathrm{mg} / \mathrm{L}$; Taz, tazobactam at $4 \mathrm{mg} / \mathrm{L}$; Imp, imipenem; Mem, meropenem; Ak, amikacin; Gm, gentamicin; Chl, chloramphenicol; Tc, tetracycline; Smx, sulphamethoxazole; Cip, ciprofloxacin; ND, not determined.

*Plasmid pPZ1 carried the PER-1 $\beta$-lactamase-encoding gene cloned from $P$. aeruginosa RNL-1. ${ }^{6}$

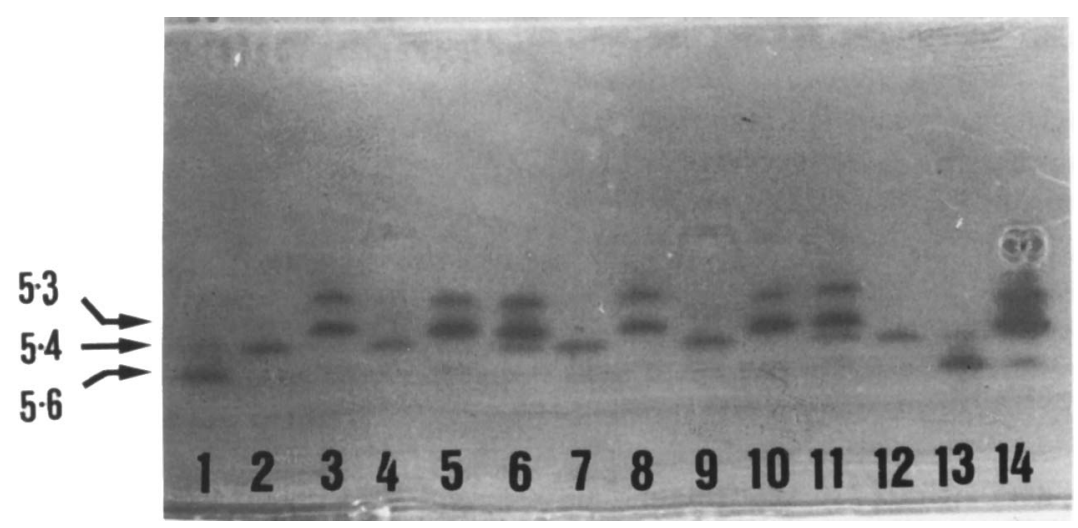

Fig. 1. Iso-electric focusing patterns of $\beta$-lactamases from the salmonella isolates, their transconjugants and their transformants. Track 1 , TEM-2 enzyme; 2, TEM-1; 3, isolate B (TEM-1 + PER-1); 4, B ampr ${ }^{\mathrm{r}}$ (TEM-1); 5, B trfm (PER-1); 6, B trcj (TEM-1 + PER-1); 7, TEM-1;

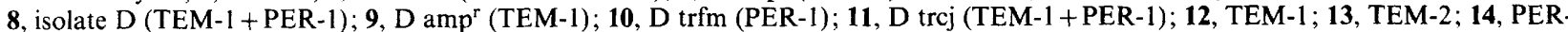
1. Note that the TEM-1 band is barely visible in the extracts of the two isolates; it was apparent when large amounts of extract were applied to the gel but, under these circumstances, the rapidly-diffusing reaction from the PER-1 enzyme precluded successful photography.

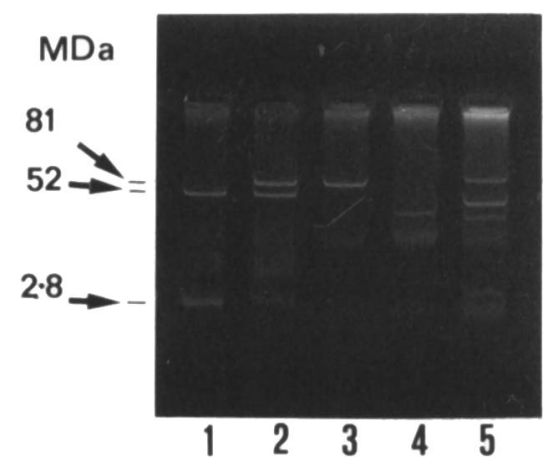

Fig. 2. Plasmids of transconjugants and transformants of isolate $B$. Track 1, B amp ${ }^{\mathrm{r}}(2 \cdot 8-$ and 52-MDa plasmids); 2, B trcj $(2 \cdot 8,52$ and $81 \mathrm{MDa})$; 3, B trfm (81 MDa); 4, pUZ8 (40 MDa); 5, NCTC 50192. Similar results were obtained for isolate $D$, its tranconjugants and transformants.

transconjugants and the plasmid itself (mol. wt $40 \mathrm{MDa}$ ) was not found. It seems that pUZ8 facilitated transfer of the 81-MDa plasmid, rather than combining with it, but a more complex re-arrangement has not been ruled out.
Kesistance to cephalosporins was also transferred to E. coli $\mathrm{K}-12$ J53-1 by transformation with total plasmid DNA extracted from strains $B$ and $D$. The transformants thereby obtained were designated $E$. coli $\mathrm{K}-12 \mathrm{~J} 53-1$ (B trfm) and J53-1 (D trfm). They were similarly resistant as $E$. coli $\mathrm{K}-12 \mathrm{~J} 53-1$ (B trcj) and J53-1 (D trcj), except to piperacillin (MIC $16 \mathrm{mg} / \mathrm{L}$ for the transformants, $512 \mathrm{mg} / \mathrm{L}$ for the transconjugants) (table II). The transformants acquired only the pI 5.3 enzyme, not the 5.4 type, and only the $81-\mathrm{MDa}$ plasmid, not the 52- and 2-8-MDa plasmids. The $81-$ MDa plasmid was confirmed to contain sequences that hybridised with the PER-1 gene probe.

\section{$P C R$ amplification and sequencing of bla ${ }_{\mathrm{PER}-1}$}

Primers A and D were used to amplify the PER gene from the $E$. coli transformants. In each case, a PCR product of $c .926 \mathrm{bp}$ was detected by agarose gel electrophoresis and ethidium bromide staining, and was confirmed to hybridise with the PER gene probe. 
The sequence of this product was determined with the aid of the primers PER A, PER B and PER C, and proved identical to the $b l a_{\mathrm{PER}-1}$ sequence reported by Nordmann and $\mathrm{Naas}^{16}$ except that guanine at position 386 was replaced by adenine. This change altered a codon from GCG to GCA but would not change the amino acid (alanine) encoded.

\section{Discussion}

This study demonstrated that PER-1 $\beta$-lactamase, albeit with one silent mutation to its encoding gene, caused resistance to third-generation cephalosporins in two isolates of $S$. typhimurium obtained in Istanbul, Turkey. One of these organisms was a representative from a series of neonatal meningitis cases seen at a teaching hospital on the Asian side of the Bosphorus; the other was from a gastro-enteritis patient who presented at the hospital on the European side of the Bosphorus. In each isolate the PER-1 enzyme was coded by an 81-MDa plasmid, that also determined resistance to aminoglycosides and chloramphenicol. Despite their great similarity in antibiogram, plasmid profiles and biochemical reactions, these two isolates were epidemiologically distinct and were of different phage types. These phage types were unrelated (L. Ward, personal communication).

This is the third report of PER-1 $\beta$-lactamase, but the first to concern enterobacteria rather than Pseudomonas aeruginosa. Production of the enzyme has not, as yet, been demonstrated in any isolate that cannot be traced back to Turkey. The original producer strain, $P$. aeruginosa RNL-1, was obtained in Paris but was from a patient transferred from Ankara (P. Nordmann, personal communication) and 14 further $P$. aeruginosa isolates with the enzyme were detected amongst ceftazidime-resistant $P$. aeruginosa strains collected at Hacettepe University Hospital, Ankara during 1991-1993. ${ }^{15}$ The finding of PER-1 $\beta$ lactamase in enterobacteria is surprising since the original enzyme from strain RNL-1 had a promotor that failed to give expression in enterobacteria $;^{16}$ nevertheless the codon usage of $b_{\text {PER-1 }}$ suggests an origin outside pseudomonas. ${ }^{16}$

Production of PER-1 enzyme was plasmid-mediated in the present isolates, being coded by an 81-MDa element. The enzyme gene was found on two different large ( $>100 \mathrm{MDa}$ ) plasmids among the $P$. aeruginosa isolates from Hacettepe Hospital ${ }^{15}$ and, contrary to what was initially thought, ${ }^{6}$ is coded by a plasmid in strain RNL-1 (Danel and Livermore, unpublished observations). Detection of bla $a_{\mathrm{PER}-1}$ on several different elements suggests that the gene may be transposon-borne, as are the genes encoding many other class A $\beta$-lactamases.

When it was not accompanied by TEM-1 enzyme, PER-1 $\beta$-lactamase gave marked cephalosporin resistance in $E$. coli but only slightly reduced susceptibility to piperacillin. Cephalosporin resistance was substantially reversed by clavulanate, although not by tazobactam. Similar resistance patterns arise when PER-1 enzyme is produced by $P$. aeruginosa. ${ }^{15}$ By contrast, the extended-spectrum TEM and SHV $\beta$ lactamases, give substantial piperacillin resistance in enterobacteria and can be inhibited by both tazobactam and clavulanate.

The emergence of extended-spectrum $\beta$-lactamases in salmonellae merits concern. These organisms are frequent causes of neonatal meningitis in many developing countries, and are often already resistant to ampicillin and chloramphenicol. Cefotaxime and ceftriaxone are rational alternative treatments, although other cephalosporins are compromised by poor CSF penetration and inadequate killing of intracellular bacteria. ${ }^{17}$ However, cefotaxime and ceftriaxone will be lost as therapy if extended-spectrum $\beta$-lactamases, such as PER-1, become prevalent in the genus. The physician then will be forced to use quinolones, which have poor CSF penetration and potential side-effects on cartilage development. Of the four neonates considered here, three received ciprofloxacin but only one survived. Meropenem may be an option in the future, being stable to extendedspectrum enzymes including PER-1, and, unlike imipenem, suitable for use in meningitis. As yet, however, this drug has not been validated or licensed for neonatal use.

We are grateful to Brigid Duke and Ismail Sisman for excellent technical assistance and to the Laboratory of Enteric Pathogens, PHLS Central Public Health Laboratory, London, and Mikrobioloji AD, Capa Tip Fakultesi, Istanbul, for typing the isolates.

\section{References}

1. Anğ O, Töreci K, Anğ-Kücüker M. Salmonellae and salmonellosis in Turkey. In: Cabello $\mathrm{F}$, Hormaeche $\mathrm{C}$, Mastroeni P, Bonina L (eds) Biology of salmonella. (NATO ASI series 245). New York, Plenum Press. 1993: 25-33.

2. Bryan JP, Scheld WM. Therapy of experimental meningitis due to Salmonella enteritidis. Antimicrob Agents Chemother 1992; 36: 949-954.

3. Hammami A, Arlet G, Ben-Redjeb SB et al. Nosocomial outbreak of acute gastroenteritis in a neonatal intensive care unit in Tunisia caused by multiply drug resistant

Salmonella wien producing SHV-2 beta-lactamase. Eur $J$ Clin Microbiol Infect Dis 1991; 10: 641-646.

4. Poupart M-C, Chanal C, Sirot D, Labia R, Sirot J. Identification of CTX-2, a novel cefotaximase from a Salmonella mbandaka isolate. Antimicrob Agents Chemother 1991 ; 35: 1498-1500.

5. Moosdeen F, Cheong YM. Enzymes of $\beta$-lactam-resistant salmonella strains. $J$ Antimicrob Chemother 1989; 23: 797-798.

6. Nordmann P, Ronco E, Naas T, Duport C, Michel-Briand Y, Labia R. Characterization of a novel extended-spectrum $\beta$ lactamase from Pseudomonas aeruginosa. Antimicrob Agents Chemother 1993; 37: 962-969. 
7. Coetzee JN, Datta N, Hedges RW. R-factors from Proteus rettgeri. J Gen Microbiol 1972; 72: 543-552.

8. Hedges RW, Matthew M. Acquisition by Escherichia coli of plasmid-borne $\beta$-lactamases normally confined to Pseudomonas spp. Plasmid 1979; 2: 269-278.

9. Threlfall EJ, Rowe B, Ferguson JL, Ward LR. Characterization of plasmids conferring resistance to gentamicin and apramaycin in strains of Salmonella typhimurium phage type 204c isolated in Britain. $J$ Hyg 1986; 97: 419-426.

10. Kado Cl, Liu S-T. Rapid procedure for detection and isolation of large and small plasmids. $J$ Bacteriol 1981; 145: 1365-1373.

11. Seetulsingh PS, Hall LMC, Livermore DM. Activity of clavulanate combinations against TEM- $\beta$-lactamaseproducing Escherichia coli isolates obtained in 1982 and 1989. J Antimicrob Chemother 1991; 27: 749-759.

12. Sambrook J, Fritsch EF, Maniatis T. Molecular cloning: a laboratory manual, 2nd edn. Cold Spring Harbor, NY, Cold Spring Harbor Laboratory Press. 1989.
13. Davis LG, Dibner MD, Batley JF. Basic methods in molecular biology. New York, Elsevier Science Publishing Co., 1986.

14. Matthew M, Harris AM, Marshall MJ, Ross GW. The use of analytical isoelectric focusing for detection and identification of $\beta$-lactamases. J Gen Microbiol 1975; 88: 169-178.

15. Danel F, Hall LMC, Gur D, Akalin HE, Livermore DM. Transferable production of PER-1 $\beta$-lactamase in Pseudomonas aeruginosa. I Antimicrob Chemother 1995; 35: 281-294.

16. Nordmann P, Naas T. Sequence analysis of PER-1 extendedspectrum $\beta$-lactamase from Pseudomonas aeruginosa, and comparison with class A $\beta$-lactamases. Antimicrob Agents Chemother 1994; 38: 104-114.

17. Cherubin CE, Eng RHK, Snith SM, Goldstein EJC. Cephalosporin therapy for salmonellosis. Questions of efficacy and cross resistance with ampicillin. Arch Intern Med 1986; 146: 2149-2152. 